\title{
Chunks of Winter
}

On the afternoon of June 3, 1959, Selden,... Kansas, suffered one of the most severe hailstorms in the State's record. In contrast to most severe hailstorms, there was little wind and the stones were small...

Late in the afternoon, about 5:15 p.m., the hail began and with the initial stones the wind was quite strong and quickly changed directions breaking many windows. The wind soon quieted over the area but hail continued to fall incessantly until 6:40 p.m.

The area covered by the hail was elongated, about 9 miles northeast to southwest and 6 miles across at the widest.....

The hail accumulated to a depth of 18 inches and was mostly pea or marble size and many of the stones were soft. Drifts were 3 to 4 feet deep at the sides of buildings where it fell from the roofs. Piles along the streets and roads remained for 2 days. Traffic on U.S. Highway 83 was halted, and approximately 100 automobiles were stalled 4 hours, or more, until bulldozers could open the roads. Snow plows were unable to move the weight.
The Red Cross reported 2 business buildings destroyed....Minor damage was indicated to almost every building in the area, 154 homes, I 25 farm buildings, and 27 business buildings. In some measure the damage was due to the continuous pelting of the stones but the greater losses resulted from the tremendous weight of accumulated hail on flat- or nearly flat-roofed buildings, causing them to collapse.The hail accumulation on a truck scale, $10 \times 45$ feet, weighed 28,000 pounds, or 62.2 pounds per square foot....

Trees were stripped of leaves and small branches, and with the ground hail-covered the town had much the appearance of winter. In just a few minutes the temperature on local thermometers dropped from near $80^{\circ}$ to $38^{\circ}$ during the storm....

A local citizen described the storm as follows, "The hail began and just didn't stop."

A news writer expressed his reaction to the scene quite well in these words, "I saw a chunk of January in the heart of June."

—from "Severe hail, Selden, Kansas, June 3, 1959," by A.D. Robb, in Monthly Weather Review, August 1959.

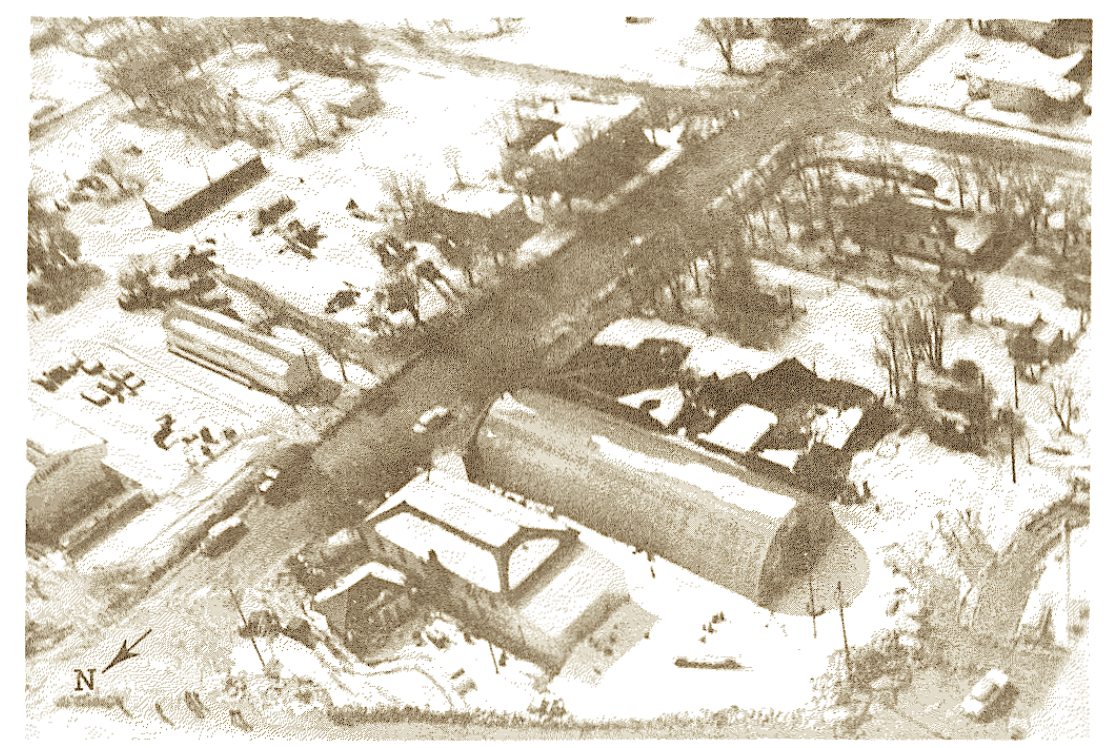

To read this article in the $B A M S$ archives, see https://doi.org/ I0.I I 75/I520-0493(I959)087<030 I:WNSHSK>2.0.CO;2 